\title{
Anisotropic Magnetoresistance of Ni-Co-Fe Alloy Nanowires Electrodeposited into Anodized Aluminium Oxide Membrane Thin Films
}

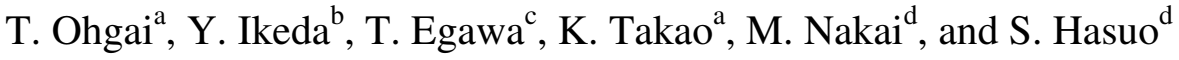 \\ ${ }^{a}$ Division of Chem. \& Mater. Sci., Nagasaki University, Nagasaki 852-8521, JAPAN \\ ${ }^{\mathrm{b}}$ Graduate School of Engineering, Nagasaki University, Nagasaki 852-8521, JAPAN \\ ${ }^{c}$ Department of Mater. Sci. \& Eng., Nagasaki University, Nagasaki 852-8521, JAPAN \\ ${ }^{\mathrm{d}}$ Kyushu Mitsui Aluminium Co. Ltd., Ohmuta, Fukuoka 836-0067, JAPAN
}

To synthesize a novel anisotropic magnetoresistance (AMR) sensor, Ni-Co, Ni-Fe, Co-Ni and $\mathrm{Co}-\mathrm{Fe}$ alloy nanowires were electrodeposited into nano-channels of anodized aluminium oxide films with the thickness ranging from $20 \mu \mathrm{m}$ to $200 \mu \mathrm{m}$. The growth rate of the nanowires was around $200 \mathrm{~nm} / \mathrm{sec}$ at the cathode potential of $-1.2 \mathrm{~V}$ vs. $\mathrm{Ag} / \mathrm{AgCl}$. The aspect ratio of the nanowires reached up to ca. 3,000 to 1 and the cylindrical shape was precisely transferred from the nano-channels to the nanowires. Magnetic hysteresis loops of $\mathrm{Ni}-\mathrm{Co}, \mathrm{Ni}-\mathrm{Fe}, \mathrm{Co}-\mathrm{Ni}$ and $\mathrm{Co}-\mathrm{Fe}$ alloy nanowires with the diameter of $60 \mathrm{~nm}$ showed typical perpendicular magnetization behaviour due to the uni-axial shape anisotropy and the coercive force reached up to $1 \mathrm{kOe} .3 .2 \%$ of AMR was observed in Co-1.5\% Ni alloy nanowires with the aspect ratio of 1,000 .

\section{Introduction}

One-dimensional nanowires with a large aspect ratio have received much attention due to their unique shape anisotropy and extremely large surface area. Holmes et al reported that defect-free Si nanowires with nearly uniform diameters ranging from 4 to $5 \mathrm{~nm}$ were grown to a length of several $\mu \mathrm{m}$ with a supercritical fluid solution-phase approach (1). They also reported that the visible photoluminescence due to quantum confinement effects was observed in Si nanowires and the photoluminescence were discrete optical transitions in the ultraviolet-visible absorbance spectra. Wang et al reported that individual and isolated InP nanowires showed highly polarized photoluminescence and photo-detection properties (2). They suggested that the intrinsic polarization anisotropy of InP nanowires could be used to create polarization-sensitive nano-scale photodetectors that may prove useful in integrated photonic circuits, optical switches, interconnects, near-field imaging, and high-resolution detectors.

Nanowires can be fabricated by manipulating metallic atoms one by one using scanning tunneling microscopy (STM) or catalyst-assisted wet chemical etching technique (3). The nanowires can be also prepared by electrochemically depositing metallic atoms into a nanochannel template with numerous nanochannels (4). Nanochannel templates such as anodized aluminum oxide films or polycarbonate membrane films with high density of nanochannels (about $10^{8} \sim 10^{10} \mathrm{~cm}^{-2}$ ) can be used in the template synthesis technique (5). Blondel et al reported that $\mathrm{Co} / \mathrm{Cu}$ and $\mathrm{Ni}-\mathrm{Fe} / \mathrm{Cu}$ 
multilayered nanowires with giant magnetoresistance (GMR) response was demonstrated (6). They synthesized the multilayered nanowires with a length of $6 \mu \mathrm{m}$, a diameter of 80 $\mathrm{nm}$ and a layer thickness of 5 to $10 \mathrm{~nm}$ into the nanochannels of ion track-etched polycarbonate membrane filters. In the report, a GMR of $14 \%$ for $\mathrm{Co} / \mathrm{Cu}$ and of $10 \%$ for $\mathrm{Ni}-\mathrm{Fe} / \mathrm{Cu}$ was demonstrated at ambient temperature in the current perpendicular to the layers. On the contrary, an array of homogeneous Ni-Co-Fe alloy would be the best candidate to be applied for magnetic field sensor with anisotropic magnetoresistance (AMR) effect $(7,8)$ as shown in Figure 1 . In this study, electrodeposition of Ni-Co-Fe alloys into a nanochannel template was investigated to synthesize novel functional ferromagnetic devices with AMR effect.
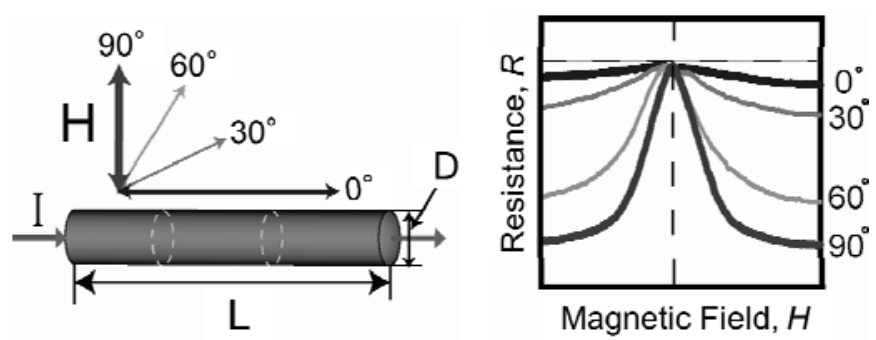

Figure 1. Anisotropic magnetoresistance effect of ferromagnetic metal nanowires. Sensor geometry (left) and resistance $R$ as a function of the magnetic field $H$ in an angle (right).

\section{Experimental}

To synthesize a novel AMR sensor, Ni-Co, Ni-Fe, Co-Ni and Co-Fe alloy nanowires were electrodeposited into nano-channels of anodized aluminium oxide films with a thickness ranging from $20 \mu \mathrm{m}$ to $200 \mu \mathrm{m}$. These anodized aluminum oxide films were used as a template for growing nanowires. On a surface of the membrane filter, a gold layer was sputter-deposited to cover the pores and form a cathode. An aqueous solution containing $\mathrm{NiSO}_{4}$ (or $\mathrm{CoSO}_{4}$ or $\mathrm{FeSO}_{4}$ ) and $\mathrm{H}_{3} \mathrm{BO}_{3}$ was used as electrolyte as shown in Table 1. Ni-Co-Fe alloy nanowires were electrodeposited into extremely long nanochannels of anodized aluminum oxide films with the thickness up to $200 \mu \mathrm{m}$. After growing the nanowires, the anodized aluminum oxide films were dissolved in an aqueous solution containing sodium hydroxide. The remains consisted of nanowires and a gold layer which served as a sample for SEM observation. Magnetic hysteresis loops and magnetoresistive curves of the nanowires were obtained using Vibrating Sample Magnetometer (VSM) and LCR meter for a magnetic field of up to $10 \mathrm{kOe}$.

Table 1. Bath compositions for electrodeposition of Ni alloy and Co alloy nanowires.

\begin{tabular}{|c|c|c|c|}
\hline & $\mathrm{Ni}$ & $\mathrm{Ni}-1.5 \% \mathrm{Co}$ & $\mathrm{Ni}-1.5 \% \mathrm{Fe}$ \\
\hline $\mathrm{NiSO}_{4} 6 \mathrm{H}_{2} \mathrm{O} \quad[\mathrm{g} / \mathrm{L}]$ & 120 & 130 & 130 \\
\hline $\mathrm{CoSO}_{4} 7 \mathrm{H}_{2} \mathrm{O}[\mathrm{g} / \mathrm{L}]$ & - & 2.0 & - \\
\hline $\mathrm{FeSO}_{4} 7 \mathrm{H}_{2} \mathrm{O}[\mathrm{g} / \mathrm{L}]$ & 一 & 一 & 2.0 \\
\hline \multirow[t]{2}{*}{$\mathrm{H}_{3} \mathrm{BO}_{3} \quad[\mathrm{~g} / \mathrm{L}]$} & 46 & 46 & 46 \\
\hline & Co & $\mathrm{Co}-1.5 \% \mathrm{Ni}$ & Co-1.5\%Fe \\
\hline $\mathrm{NiSO}_{4} 6 \mathrm{H}_{2} \mathrm{O} \quad[\mathrm{g} / \mathrm{L}]$ & - & 2.0 & - \\
\hline $\mathrm{CoSO}_{4} 7 \mathrm{H}_{2} \mathrm{O}[\mathrm{g} / \mathrm{L}]$ & 120 & 138 & 138 \\
\hline $\mathrm{FeSO}_{4} 7 \mathrm{H}_{2} \mathrm{O}[\mathrm{g} / \mathrm{L}]$ & 一 & - & 0.6 \\
\hline $\mathrm{H}_{3} \mathrm{BO}_{3} \quad[\mathrm{~g} / \mathrm{L}]$ & 46 & 46 & 46 \\
\hline
\end{tabular}




\section{Results and Discussion}

\section{$\underline{\text { Anodization Process of Aluminum }}$}

Figure 2 shows SEM images of surface sides ((a) and (d)), layer sides ((b) and (e)) and cross sections of an anodized aluminum oxide membrane filter ((c) and (f)) exfoliated from an metallic aluminum rod ((a), (b), (c) were anodized at 50V, (d), (e), (f) were anodized at $70 \mathrm{~V}$ for 2 hours). In case the sample was anodized at $70 \mathrm{~V}$, the average channel diameter was around $60 \mathrm{~nm}$ and the channel density was around $10^{8} \mathrm{~cm}^{-2}$ while the channel length was approx. $60 \mu \mathrm{m}$ for the anodization time of 2 hours. In this case, the average growth rate of the anodized aluminum oxide layer was estimated to be around $8.3 \mathrm{~nm} / \mathrm{s}$ (30 $\mu \mathrm{m} /$ hour). Ohgai et al have reported that the average growth rate of the anodized aluminum oxide layer depends on the anodization voltage and the growth rate $R_{G}^{A v e}(\mathrm{~nm} / \mathrm{min})$ increases exponentially with increasing the anodization voltage $V_{A}(\mathrm{~V})$ as shown in equation [1] (9):

$$
\log R_{G}^{A v e}=0.03 V_{A}+1
$$

According to the equation [1], if $V_{A}$ equal to $70 \mathrm{~V}, R_{G}{ }^{A v e}$ is estimated to be approx. 20 $\mathrm{nm} / \mathrm{s}$ which is quite larger than that obtained in the present work. It is well known that the real time growth rate of the anodized aluminum oxide layer $R_{G}{ }^{\text {Real }}$ decreases with increase in the oxide layer thickness. In the present work, the oxide layer thickness range is around $60 \mu \mathrm{m}$ and is much larger than that reported by Ohgai et al (9). Therefore, $R_{G}{ }^{\text {Ave }}$ obtained in the present work would be smaller than previously reported (9).
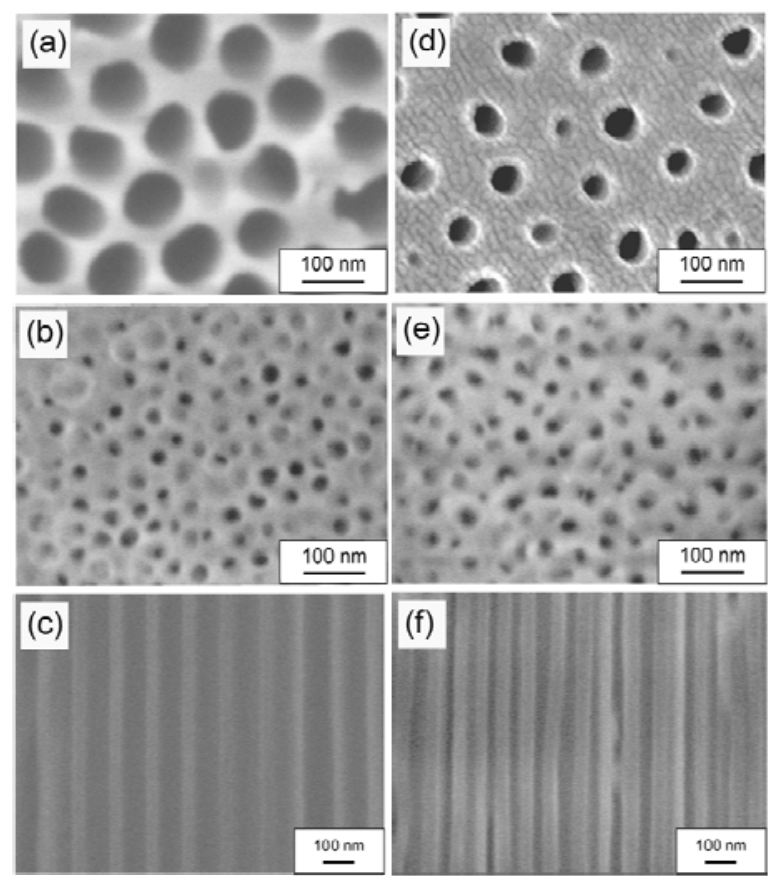

Figure 2. SEM images of surface side, barrier layer side and cross sectional side of an anodized aluminum oxide membrane filter exfoliated from a metallic aluminum rod ((a), (b), (c) at 50V, (d), (e), (f) at 70V). 
Figure 3 shows the relationship between film thickness of anodized aluminium oxide layer and anodization time. The film thickness $y(\mu \mathrm{m})$ increased with increasing the anodization time $x$ (hour) according to a parabolic low as shown in equation [2]:

$$
y=44.718 x^{0.4734}
$$

Therefore, the real time growth rate of the anodized aluminum oxide layer $R_{G}{ }^{\text {Real }}$ can be expressed by equation [3]:

$$
R_{G}^{\text {Real }}=d y / d x=21.17 x^{-0.5266}(\mu \mathrm{m} / \mathrm{hour})=5.88 x^{-0.5266}(\mathrm{~nm} / \mathrm{sec})
$$

Consequently, $R_{G}^{\text {Real }}$ decreases with an increase in the anodization time $x$ and the oxide layer thickness $y$.

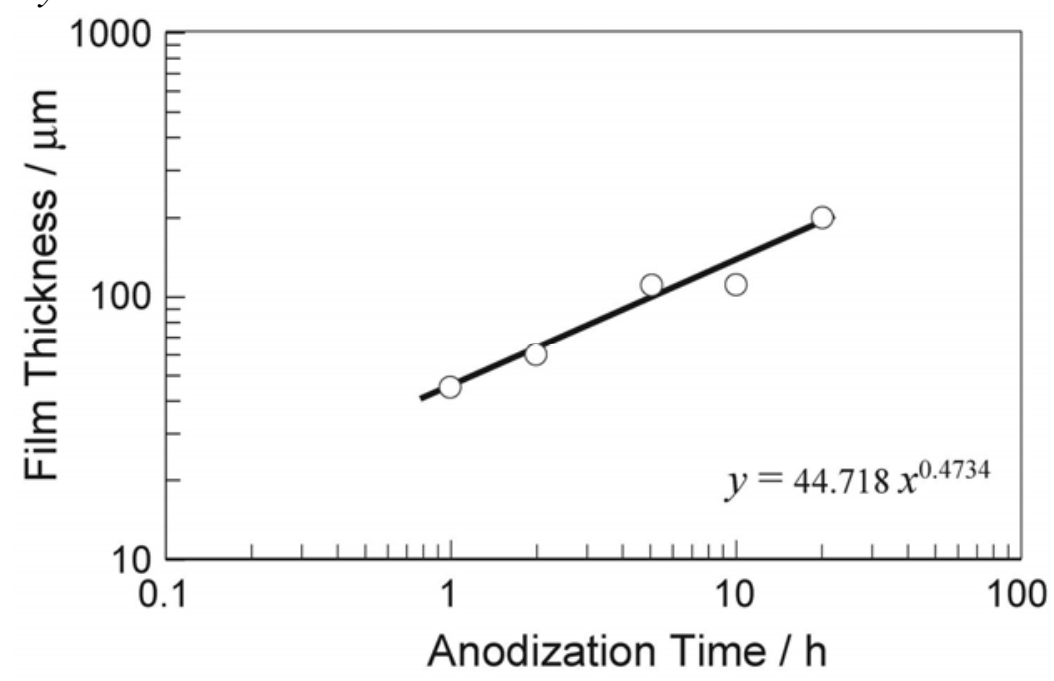

Figure 3. Relationship between film thickness of anodized aluminium oxide layer and anodization time.

\section{Magnetoresistance of Ni-Co-Fe Alloy Nanowires}

The growth rate of $\mathrm{Ni}, \mathrm{Ni}-\mathrm{Co}, \mathrm{Ni}-\mathrm{Fe}, \mathrm{Co}, \mathrm{Co}-\mathrm{Ni}$ and $\mathrm{Co}-\mathrm{Fe}$ alloy nanowires was around $200 \mathrm{~nm} / \mathrm{sec}$ at a cathode potential of $-1.2 \mathrm{~V}$ vs. $\mathrm{Ag} / \mathrm{AgCl}$. The aspect ratio of the nanowires reached up to 3,000 to 1 and the cylindrical shape was precisely transferred from the nano-channels to the nanowires. Figure 4 shows magnetization curves of electrodeposited $\mathrm{Ni}, \mathrm{Ni}-1.5 \mathrm{at} \% \mathrm{Co}, \mathrm{Ni}-0.8 \mathrm{at} \% \mathrm{Fe}, \mathrm{Co}, \mathrm{Co}-0.9 \mathrm{at} \% \mathrm{Ni}$ and $\mathrm{Co}-0.1 \mathrm{at} \% \mathrm{Fe}$ alloy nanowires with diameter of $60 \mathrm{~nm}$ and length of $60 \mu \mathrm{m}$. The magnetic field was applied in-plane and in perpendicular direction to the membrane film plane. The perpendicular direction of the membrane film plane is parallel to the long axis of the nanowires. These nanowires were hardly magnetized in in-plan direction and the magnetization reached to saturation at more than $5 \mathrm{kOe}$ as shown in Figure 4. On the contrary, these nanowires were easily magnetized in perpendicular direction and the coercive force reached up to $1 \mathrm{kOe}$. These magnetization curves revealed that the electrodeposited nanowires have a typical perpendicular magnetization behaviour due to the uni-axial shape anisotropy. Figure 5 shows magnetoresistive hysteresis of electrodeposited $\mathrm{Ni}, \mathrm{Ni}-1.5 \mathrm{at} \% \mathrm{Co}, \mathrm{Ni}-0.8 \mathrm{at} \% \mathrm{Fe}, \mathrm{Co}, \mathrm{Co}-0.9 \mathrm{at} \% \mathrm{Ni}$ and $\mathrm{Co}-0.1 \mathrm{at} \% \mathrm{Fe}$ alloy nanowires with diameter of $60 \mathrm{~nm}$ and length of $60 \mu \mathrm{m}$. As shown in Figure 5(b), in the magnetic field of in-plane direction, $\mathrm{Ni}-1.5 \% \mathrm{Co}$ alloy nanowires with the aspect ratio of 1,000 showed an AMR effect of 3.2\%, which was 1.6 times larger than that of pure Ni. 


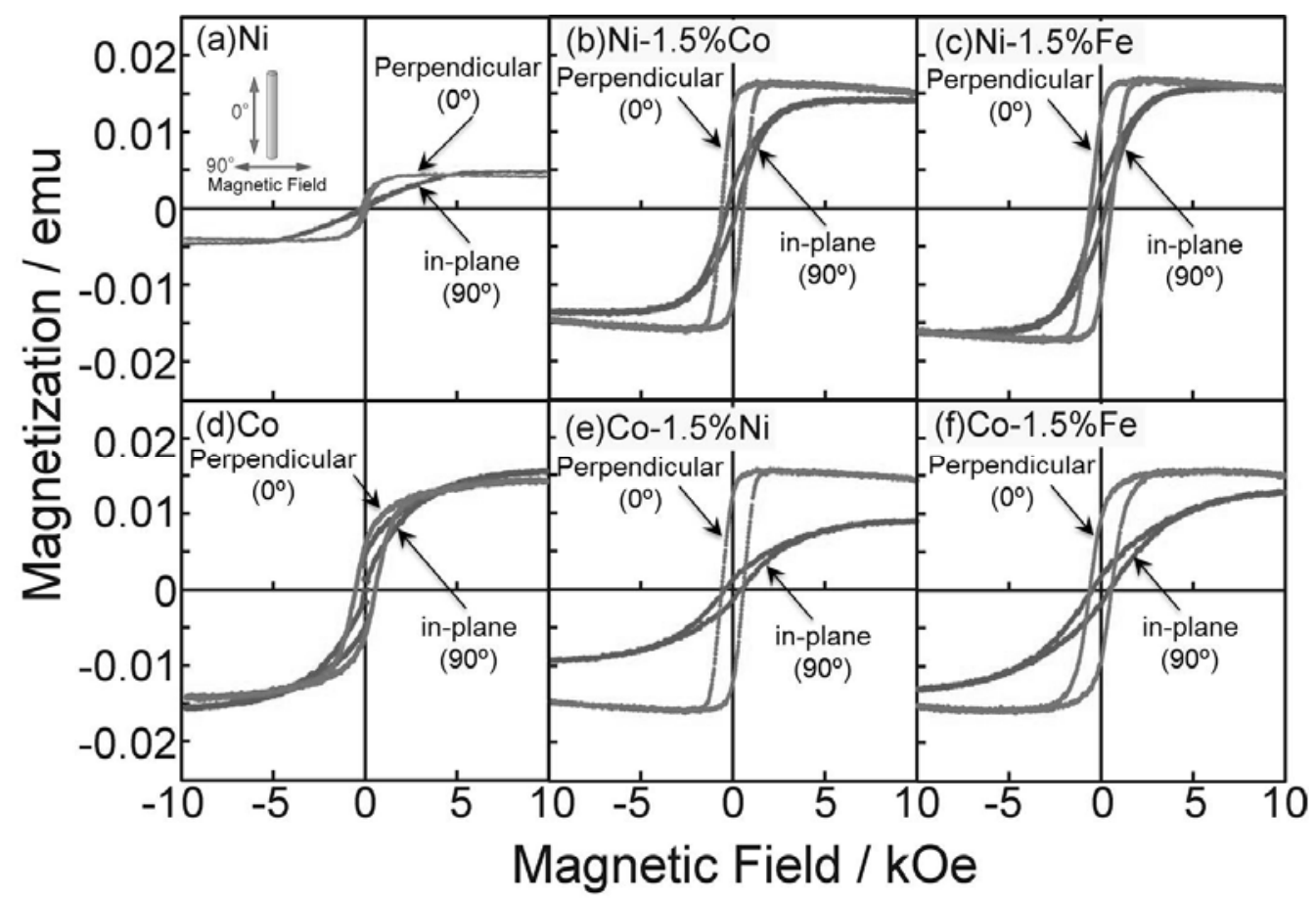

Figure 4. Magnetization curves of electrodeposited Ni, Ni-Co, Ni-Fe, Co, Co-Ni and CoFe alloy nanowires with diameter of $60 \mathrm{~nm}$ and length of $60 \mu \mathrm{m}$.

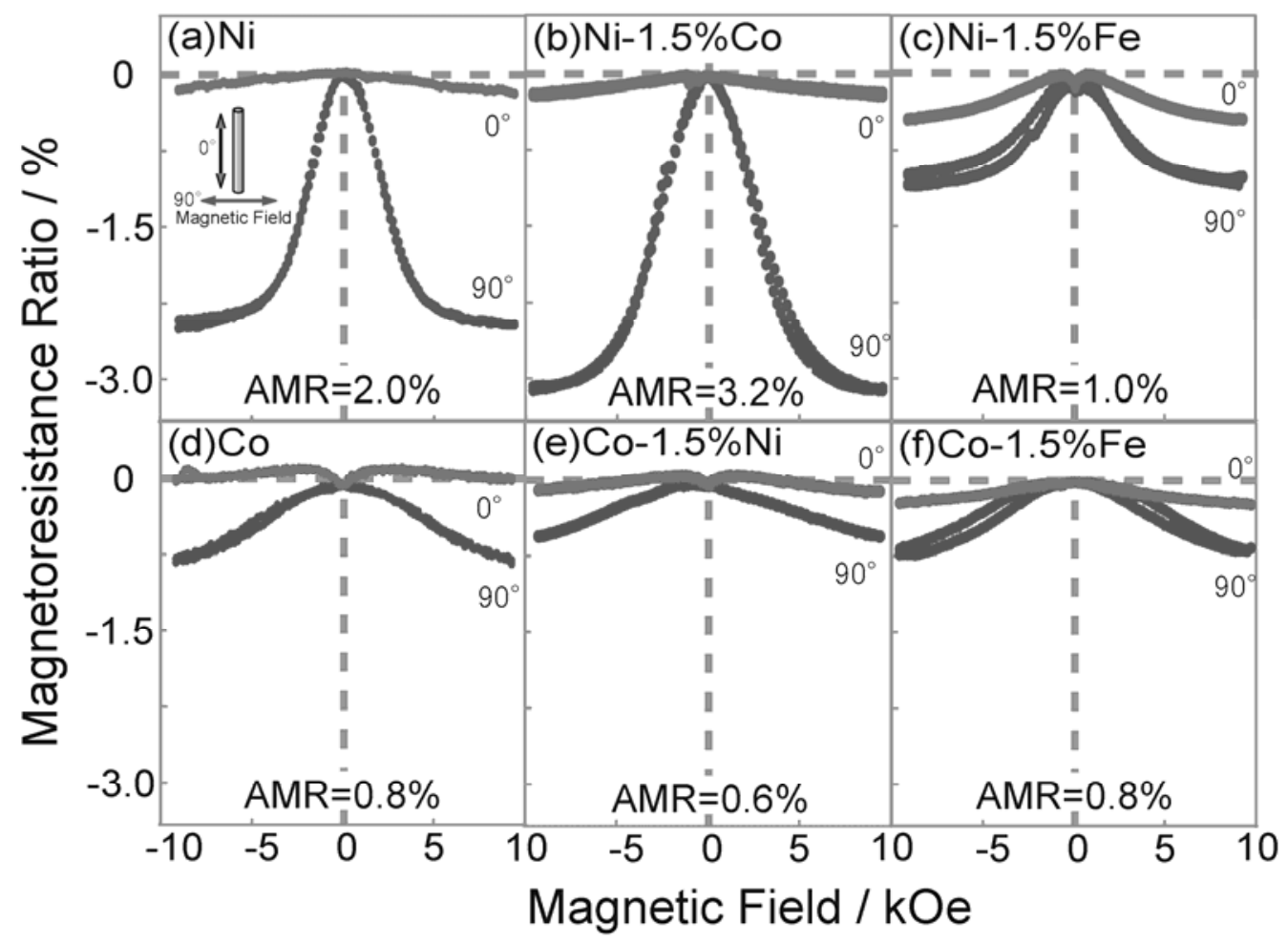

Figure 5. Magnetoresistive hysteresis of electrodeposited Ni, Ni-Co, Ni-Fe, Co, Co-Ni and Co-Fe alloy nanowires with diameter of $60 \mathrm{~nm}$ and length of $60 \mu \mathrm{m}$. 


\section{Conclusions}

Anodized aluminum oxide membrane filters with channel diameters of $60 \mathrm{~nm}$ and channel lengths ranging from $20 \mu \mathrm{m}$ to $200 \mu \mathrm{m}$ were synthesized using a bipolar continuous electrolysis process with anodic oxidation and cathodic exfoliation. Ni, Ni-Co, $\mathrm{Ni}-\mathrm{Fe}, \mathrm{Co}, \mathrm{Co}-\mathrm{Ni}$ and $\mathrm{Co}-\mathrm{Fe}$ alloy nanowires were synthesized using a electrodeposition technique. $3.2 \%$ of anisotropic magnetoresistance effect was observed in $\mathrm{Ni}-1.5 \% \mathrm{Co}$ alloy nanowires electrodeposited into anodized aluminum oxide template with very large aspect ratio of ca. 1,000 .

\section{Acknowledgments}

This work was supported in part by Kyushu Industrial Technology Center, Mitutoyo Association for Science \& Technology, Yazaki Memorial Foundation for Science \& Technology and Research Foundation for Materials Science.

\section{References}

1. J.D. Holmes, K.P. Johnston, R.C. Doty and B.A. Korgel, Science, 287, 1471 (2000).

2. J. Wang, M.S. Gudiksen, X. Duan, Y. Cui and C.M. Lieber, Science, 293, 1455 (2001).

3. D.J. Kim, J.K. Seol, M.R. Lee, J.H. Hyung, G.S. Kim, T. Ohgai and S.K. Lee, Appl. Phys. Lett., 100, 163703 (2012).

4. C. R. Martin, Adv. Mater. 3, 457 (1991).

5. R. Spohr, C. Zet, B.E. Fischer, H. Kiesewetter, P. Apel, I. Gunko, T. Ohgai and L. Westerberg, Nucl. Inst. Meth. Phys. Res. B, 268, 676 (2010).

6. A. Blondel, J.P. Meier, B. Doudin and J.P. Ansermet, Appl. Phys. Lett., 65, 3019 (1994).

7. T. Ohgai, I. Enculescu, C. Zet, L. Westerberg, K. Hjort, R. Spohr and R. Neumann, J. Appl. Electrochem., 36, 1157 (2006).

8. T. Ohgai, K. Hjort, R. Spohr and R. Neumann, J. Appl. Electrochem., 38, 713 (2008).

9. T. Ohgai, L. Gravier, X. Hoffer, M. Lindeberg, K. Hjort, R. Spohr and J.P. Ansermet, J. Phys. D: Appl. Phys., 36, 3109 (2003). 